REGARDS

SUR L'ECONOMIE ALLEMANDE

BULLETIN ECONOMIQUE DU CRAC

\section{Regards sur l'économie allemande}

Bulletin économique du CIRAC

$114 \mid 2014$

Varia

\title{
Succès d'estime relatif mais prometteur pour Manuel Valls
}

\section{René Lasserre}

\section{(2) OpenEdition}

Édition électronique

URL : http://journals.openedition.org/rea/4720

DOI : $10.4000 /$ rea. 4720

ISSN : 1965-0787

Éditeur

CIRAC

\section{Édition imprimée}

Date de publication : 1 octobre 2014

Pagination : 1-2

ISSN : 1156-8992

\section{Référence électronique}

René Lasserre, "Succès d'estime relatif mais prometteur pour Manuel Valls », Regards sur l'économie allemande [En ligne], 114 I octobre 2014, mis en ligne le 01 octobre 2014, consulté le 22 septembre 2020. URL : http://journals.openedition.org/rea/4720 ; DOI : https://doi.org/10.4000/rea.4720 


\section{Succès d'estime relatif mais prometteur pour Manuel Valls}

Lors de sa première visite de chef de gouvernement en Allemagne, les 22 et 23 septembre derniers, Manuel Valls s'est vu accorder un réel succès d'estime en présentant le programme de réformes de son nouveau gouvernement, d'abord à la Chancelière Angela Merkel et à son ministre de l'économie Sigmar Gabriel, puis devant les chefs d'entreprise du BDI rassemblés pour la Journée de l'Industrie à Hambourg. Alors que la Chancelière et le Vice-Chancelier ont salué les ambitions et la cohérence de ce programme, les industriels ont vivement apprécié la détermination du Premier ministre à vouloir le mettre en œuvre. Mais audelà de l'accueil chaleureux et de la qualité d'écoute qui lui ont été réservés, ce dernier n'a pas réussi à gagner pleinement la confiance de ses interlocuteurs ni de l'opinion allemande, tant est lourd le passif de crédibilité politique accumulé par la France auprès de son principal partenaire européen.

Le non-respect répété, par le gouvernement français, des règles budgétaires du Pacte de stabilité et de croissance européen, confirmé par une nouvelle et troisième demande de report de mise en conformité à la règle des $3 \%$, vient à l'évidence de faire monter d'un cran le désarroi, sinon l'exaspération des dirigeants des milieux politiques et économiques allemands. Le temps semble révolu où la France tentait de justifier ses accommodements avec la discipline budgétaire en entretenant la controverse sur la pertinence et les conditions d'application des critères. Depuis le début de la présidence de François Hollande, la France n'a cessé de contester ouvertement le bien-fondé d'une politique de stabilité européenne au service de la monnaie commune et, au nom d'une politique de soutien à la croissance dont elle persiste à vouloir se faire le chef de file, elle s'est exonérée de fait de ses engagements en remettant délibérément à plus tard les ajustements nécessaires.

Face au constat de l'échec économique et à la situation politique critique où la France se trouve désormais placée vis-vis des autorités de Bruxelles, il ne fallait guère s'attendre à ce que nos partenaires allemands, à la faveur de l'annonce d'un changement de cap, fassent preuve d'une mansuétude particulière. Et encore moins qu'ils délivrent une quelconque forme d'indulgence avant même que les instances de l'UE soient appelées à statuer sur d'éventuelles sanctions. Inversement, la proclamation d'un ambitieux programme de réformes a-t-elle été accueillie avec d'autant plus de bienveillance et d'intérêt qu'elle était depuis très longtemps attendue.

Les conditions laborieuses de gestation d'un programme qui a finalement exigé pas moins de deux remaniements ministériels pour se concrétiser en projet politique, et dont la mise en œuvre n'est que partiellement engagée, suscitent en Allemagne quelque perplexité ou justifient pour le moins l'expectative. Autant d'éléments d'incertitude qui, visiblement, n'ont pas permis à Manuel Valls d'emporter d'emblée la convic-

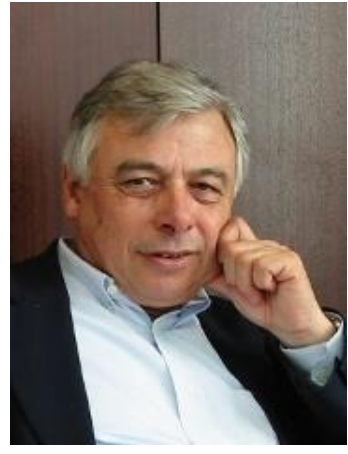

Prof. René Lasserre, Directeur du CIRAC 
tion de la communauté des décideurs allemands, habitués à des choix politiques et des engagements contractuels généralement mieux cadrés et autrement contraignants.

Mais en raison même de ces éléments de circonstance, ne peut-on pas justement considérer que c'est l'équation personnelle de Manuel Valls, son courage et sa détermination à promouvoir le changement qui, de Berlin à Hambourg, ont été en quelque sorte salués, pour ne pas dire à demi plébiscités, tant ils semblent à la fois marquer une rupture de style et annoncer une nouvelle phase dans le couple franco-allemand ? Outre qu'il se réclame d'un socialisme ouvert à la logique du marché et qu'il incarne un pragmatisme ouvert à la modernité, le nouveau Premier Ministre apparaît Outre Rhin comme la promesse d'une rupture avec l'immobilisme idéologique et politique de la gauche française dont, au fil des mois, François Hollande a fini par apparaître en Allemagne, pardelà son apparence moderniste, et sans doute à ses dépens, comme un fidèle archétype.

Pour peu qu'elle soit durable, cette nouvelle donne devrait permettre de refonder le dialogue économique et social franco-allemand sur des bases plus constructives. Une France qui s'engage résolument dans un processus de modernisation de son modèle économique et social tirera grand profit des échanges d'expérience avec ses voisins, en particulier à l'échelon de coopérations territoriales ou sectorielles. Au niveau national, la mise en convergence des politiques économiques et sociales permettra de dépasser les clivages doctrinaux. Elle ouvrira des marges de manœuvre et créera un contexte de confiance plus favorable au développement de politiques communes et de projet conjoints, notamment en matière d'innovation et d'investissement.

Dans un premier temps, l'évolution du débat économique franco-allemand sous l'effet du déblocage de l'action réformatrice en France, conjuguée à l'initiative annoncée par le nouveau président de la Commission, Jean-Claude Junker, devrait contribuer à donner corps à un programme européen de relance de l'investissement. Celui-ci, doté de 300 milliards d'Euros et placé sous l'égide de la BEI, devrait bientôt concerner des secteurs prioritaires tels que l'énergie, le numérique et l'innovation.

Reste qu'en dépit des espoirs qu'il peut susciter, le crédit politique engrangé par Manuel Valls auprès de ses interlocuteurs allemands apparaît fragile. Tout d'abord dans l'ambivalence des discours que tient le Premier ministre entre Berlin et Paris lorsqu'il proclame devant une majorité indocile à l'Assemblée nationale l'entière souveraineté de décision de la France et garantit la sauvegarde des pans essentiels mais lézardés du modèle social français. Ensuite, et surtout, dans les sérieuses incertitudes dont sont entachées les nouvelles prévisions présentées pour le budget 2015 en vue d'assurer le retour au seuil des $3 \%$ en 2017, lesquelles ne manqueront pas d'être évaluées sévèrement lors de leur prochain examen à Bruxelles.

Bon courage à Manuel Valls !

René Lasserre, le 3 octobre 2014 